\title{
Hospital Institutional Context and Funding
}

\author{
Carine Milcent ${ }^{1}$ \\ PSE - CNRS \\ Carine.milcent@psemail.eu
}

In this Chapter, we decide to separate the hospital by ownership (public/private). Because of the historical healthcare system context, the public sector is more mature than the private ones. As a consequence, some pilot reforms are introduced only in the public sector. As example, the implementation of a DRG-based payment presented at the end of the first section of this Chapter is a good illustration. Actually, it does not mean that the private sector will be immune of these new forms of funding. In the US for instance, when the DRG-based payment has been introduced, it was designed for Medicare patient (patients aged over 65 years old) without focusing on a specific hospital ownership by also targeting private hospitals.

\section{Public health establishments}

\section{Institutional Context}

Ownership: After the implementation of the " three-tier public provision system », most hospitals were under direct supervision from Health Ministry, with support from local Health Offices. Nevertheless, some remained were depending from state-owned companies or the army. Other governing bodies were involved in maternities and family planning centers, at county and township level. Whatever the governing body, the healthcare supply was provided by the public sector.

Today, health centers in both rural and urban areas are split between public and private structures. In rural zones, community clinics are mostly private whereas urban county hospitals remain mostly public.

Comparing Figure 1 to Figure 2 illustrates that the healthcare supply shift from public sector to private sector is an ongoing process.

Figure 1 : Ownership and Healthcare Services in 2006

\footnotetext{
${ }^{1}$ French National Center for Scientific Research (CNRS), Paris, France; Paris School of Economics (PSE), Paris, France. 48, boulevard Jourdan 75014 Paris
} 


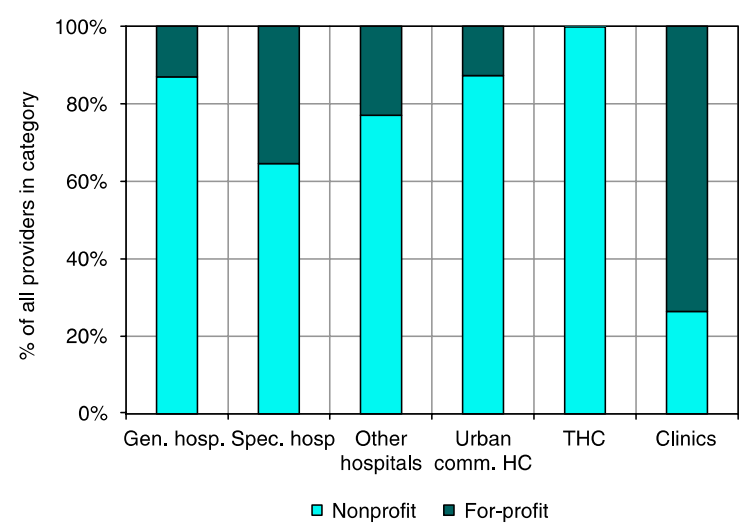

Note: Data are from the 2006 MOH Health Statistical Digest (online) (Ministry of Health, 2006) and refer to 2005. Estimates exclude a small number of providers $(<1 \%)$ that have not yet been classified. The "nonprofit" category mainly consists of organizations owned by government and companies (available data do not permit a disaggregation of the nonprofit category by ownership)

Figure 2: Ownership and Healthcare Services in 2012

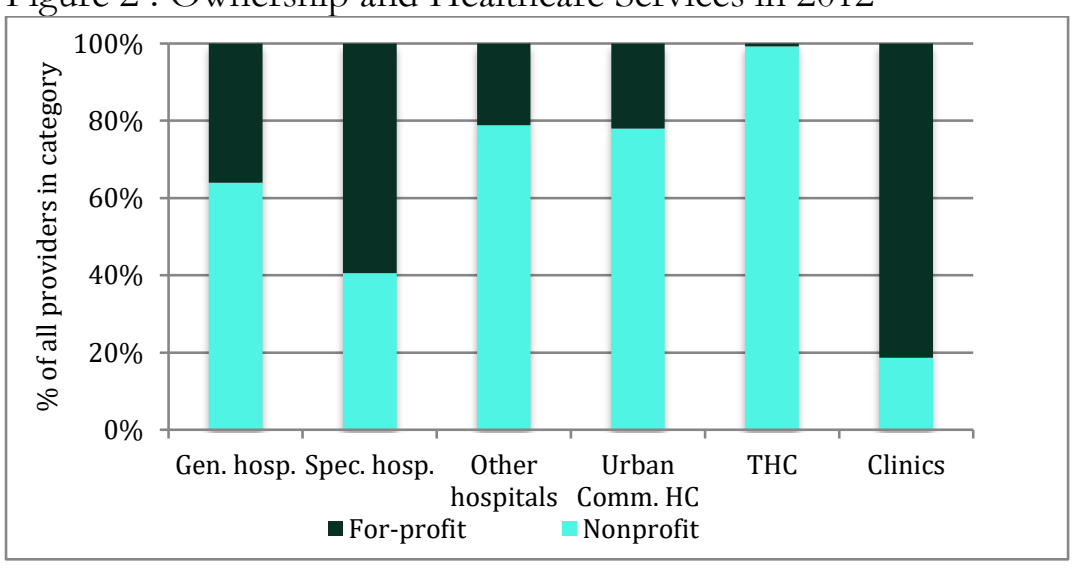

Note: Data are from the 2012 MOH Health Statistical Digest (online) (Ministry of Health, 20012) and refer to 2011. Estimates exclude a small number of providers (<1\%) that have not yet been classified. The "nonprofit" category mainly consists of organizations owned by government and companies (available data do not permit a disaggregation of the nonprofit category by ownership)

Governing bodies: Public hospitals are mostly under supervision from Health Ministry but not solely. There still is a certain number of governing bodies, ministries or state-owned companies that are directly involved in management of hospitals. For instance, the People's Liberation Army (PLA) and some large state-owned industries such as the railways have their own hospitals and medical schools. Most hospitals and medical schools affiliated with PLA are considered to be of high quality and provide services to political leadersi ${ }^{\mathrm{i}}$.

This fragmented structure is a hurdle for the implementation of any hospital reform, with four main Ministries involved: the National Develpment and Reform Commission (NDRC), the Ministry of Human Resources and Social Security (MoHRSS), the Ministry of Finance (MoF) and obviously the Ministry of Health (MoH). These ministries do not have the same objective. As a consequence, the healthcare suppliers do not response to the same incentives. It leads to a lack of coordination between the 
healthcare providers. The effect of the reforms implemented may be affected by this multiplicity of governing body.

The SARS epidemics in 2003 has crystallized the importance of public health and care. Many expert and officials have pointed out the flaws in the health systems that had led to the quick spread of the SARS virus ${ }^{\text {ii. }}$. As a consequence, a think tank was created to give the strategic direction of future reforms. It is called Development Research Center (DRC) and depends from the Chinese State Council. One of its report heavily influenced the 2009 reform package $e^{\mathrm{iii}}$.

To solve the complexity of Chinese health system reforms' implementation, a cross-ministry group was set up. On top of ministries, a cross-ministries group was set up in 2006 to facilitate the implementation of hospital reform. This Leading Group for Coordination Healthcare System Reform was depending from the NDRC and Health Ministry and first chairman was future Prime Minister Li Keqiang.

In 2008, this group in the state council was restructured with mission to coordinate all stake-holders of healthcare reforms, from provincial governments to ministries involved and administrations in charge of implementing reforms. ${ }^{\text {iv }}$ It made various and important policy initiatives at the central level. . This leading group consists of representatives from twenty ministries including $\mathrm{MoH}$, MoHRSS, MoF and NDRC. As a support, one agency from each of the four main ministries is in charge of a specific part of the reform. Resources from other governing are also tapped for more specialized aspects (see table 1). Besides, every province set up a local team for health reform. They are in charge of a specific check-list of tasks from the state council that can be completed by the provincial authority.

Table 1: Agencies in charge of healthcare reform

\begin{tabular}{|l|l|}
\hline Governing body & Role \\
\hline Ministry of Health (MoH) & $\begin{array}{l}\text { Healthcare service per se, public hospital } \\
\text { reform, rural cooperative schemes, list of } \\
\text { authorized medicines and medical devices, } \\
\text { long term planning }\end{array}$ \\
\hline $\begin{array}{l}\text { National Development and Reform } \\
\text { Commission (NDRC) }\end{array}$ & $\begin{array}{l}\text { Payment rules and regulation, national list of } \\
\text { reimbursed medicines, training }\end{array}$ \\
\hline $\begin{array}{l}\text { Ministry of Human Resources and Social } \\
\text { Security (MoHRSS), }\end{array}$ & State-financed health insurance \\
\hline Ministry of Finance (MoF) & \begin{tabular}{l} 
Investment in healthcare \\
\hline $\begin{array}{l}\text { State Food and Drug Administration of China } \\
\text { (SFDA) }\end{array}$
\end{tabular} $\begin{array}{l}\text { Safety of care products and care related } \\
\text { products }\end{array}$ \\
\hline State Intellectual Property Office (SIPO) & $\begin{array}{l}\text { Patent regulation and application on the } \\
\text { domain of healthcare }\end{array}$ \\
\hline China Insurance Regulatory Council (CIRC) & $\begin{array}{l}\text { Organization and regulation of private } \\
\text { insurance market }\end{array}$ \\
\hline
\end{tabular}

Source: US-China Business Council

As a consequence, all reforms implemented since 2009 are not coordinated by the Ministry of Health but by a special unit reporting directing to the State Council (or more precisely to the Health reform Office of the State Council). Yet, this unit does not have the capability to actually implement the decisions taken. Its needs to go the ministries to execute decisions. In reality, these reforms involve a large numbers of governing bodies. The National Development and Reform Commission (NDRC) and the Ministry of Finance $(\mathrm{MoF})$ in particular have a key role. 
The different ministries involved can sometimes have conflicting priorities. For instance, if we take the example of health insurance, MoHRSS is in charge of insurance in urban areas, whereas the Ministry of Civil Affairs (MoCA) manages a program for the underprivileged that includes an insurance covering basic care. In parallel, the China Insurance Regulatory Commission_CIRC has a mission to encourage the development of a private health insurance market.

Another example is any reform touching hospital human resources. The Office of Central Institutional Organization), the Ministry of Education as well as MoHRSS, because it manages the career of civil servants are necessarily involved.

Daily governance is also complex. For instance, for investment decisions for public hospitals, two ministries share responsibility: the $\mathrm{MOH}$ and the National Development and Reform Commission (NDRC). As a result, public hospitals may receive conflicting policies and regulations.

In addition, for the execution of policies, many other bodies are involved: authorities at provincial level, district level and city level, bureaus of Labor and Social Security, Health Bureaus, Bureaus of Finance. This huge number of stakeholders show the complexity of hospital reform in China. If the central government defines the general direction and objectives, this actual implementation takes place under steering at a more granular level, provincial and below. This, combined with a large financial autonomy, makes it possible to factor in local specificities in the actual execution of reforms but can also generate important territorial inequalities. A costly reform implemented in an area hit by economic downturn will not produce the same effect as when implemented in a soaring region.

To mitigate this risk, each authority in charge of implementation at local level gets measurable targets, as, for instance, the number of people covered by public health insurance at a certain date. These targets are cascaded into the individual objectives of local political leaders, having a direct impact on their career advancement and promotion into the party's apparatus. Nonetheless, many objectives of health reforms are not easily quantifiable, as for instance better governance, leaving nuances in interpretation widespread.

\section{Evolution of funding}

At the beginning of the 1980 s, the central government was paying for $60 \%$ of hospital expenditures. Over the 1979-1991 period, the government introduced a co-payment system in healthcare establishments. The aim was to provide greater flexibility in terms of profit, and thus to incite establishments to improve the quality of the services they offered and professionalize their medical staff $(\mathrm{Du}, 2009)^{\mathrm{v}}$. In 1992, the Ministry of Health officially granted greater autonomy to public hospitals, through an official document published in September 1992 by the State Council, "Instructions on Health Reform »". By this, they were authorized to deliver paid services and to make profit, but were made responsible for their losses and debts. They have to self-finance their investment in equipment and infrastructure as well as salary bonus policy. They are also entitled to enter into joint-ventures with private companies, including to set-up for-profit departments within the public itself. As a result of this 1992 reform, bigger hospital structures developed, as well as improved quality, thanks to the acquisition of high tech equipment.

Since then, Public hospitals in China have the particularity that they behave as companies, aiming at maximizing profit through investment and price setting, while being governed as any traditional public structure. They are the sole recipient of public funding ${ }^{\text {vii }}$, be it from the central or local governments. Staff management is under supervision from central governing bodies, mainly the 
MoRHSS, from both resource allocation perspective as well as individual career management. While they keep this strong bond to central authorities, they have financial autonomy. They are able to determine their price policy, which can turn out to be a problem in cases where they are in a monopoly situation in certain geographical areas, hence without market regulation of pricing.

By 2003 central government funding had fallen to $8 \%$ of hospital expenditures. The fall in state financing was offset by charging for medicine and other diagnosis procedures. In China, as in many other Asian countries, doctors are not consulted in their doctor's office _outside any healthcare facilities_, but in the hospital outpatient department. The prescription is given at the end of the consultation by default (patients are not asked if they want to purchase them). The total cost is the sum of the price of the consultation and that of the prescribed medicine. Patients do not have an explicit choice of not accepting the doctor's prescription. In this context, prescription prices can be varied in order to compensate for the fall in the hospital's central funding. This practice has been severely questioned during the recent healthcare reforms in China. Prescriptions currently account for about half of healthcare expenditures. The over-prescription of medicine and the overuse of high-tech equipment for diagnostic purposes have often been identified as the cause of the rapid increase in healthcare expenditures (Eggleston et al., 2008 ${ }^{\text {viii; }}$ Wang, 2005 ${ }^{\mathrm{ix}}$ ). The current healthcare system has been judged to be both too costly and more sophisticated than is medically necessary (World Bank, 2004 ; Blumenthal and Hsiao, 2005 ${ }^{\mathrm{x}}$ ). It is very likely that these factors affect the demand for and use of healthcare.

Following the 1992-reform, some public facilities set up healthcare centres with fee-for-service payment. As expected, these for-profit firms re-oriented their activity to the most profitable healthcare. These for-profit health centers did not have to provide any public-service mission. The healthcare prevention program was then neglected: epidemic control, health education, maternal and child health.

The 2003 SARS epidemics put back the public health role of public hospitals to the front of the scene. Negative side effects of financial autonomy appeared sharply in that context. This lead to a clear split between medical operations and hospital management functions. Additionally, it has been demanded to clearly split for-profit activities from the rest in hospital accountancy books ${ }^{\text {xii }}$.

Nonetheless, in 2008, health expenditures for pharmaceutical products still accounted for $43 \%$ of total health expenditures. xiiiThis is to be compared to a $17 \%$ average share in OECD countries. ${ }^{x i v}$ Per capita medicine expenditures reach $574 \mathrm{RMB}$. Nearly 40 million surgeries were performed in China in 2015. This figure is nearly one sixth of the world's total surgical operations. The biggest shares of procedures are in the area of obstetrical and gynecological, then digestive and gastrointestinal system procedures ${ }^{\mathrm{xv}}$. According to Yip et Hsiao (2015), «from 1978 to 2011, personal health spending per capita increased by a multiple of 164 from 11 RMB to 1,801 RMB (or from roughly 6 to 280 USD) while the Consumer Price Index increased by 5.65 times during this period. ${ }^{x v i, x v i i} \mathrm{~A}$ huge portion of this expenditure was for high-tech tests and unnecessary drugs. »

\section{Improving healthcare quality and Reducing hospital expenditures' funding}

In the 80 's, the main objective of the regulator was to make it possible for hospital to acquire technology and to improve their level of quality. In parallel, the aim was also from maintain to reduce the burden of hospital expenditures' funding. The series of reforms implied three main changes:

- Financial autonomy of public hospitals

- Managerial autonomy for a part of public hospitals staff 
- Physicians: Financial incentive to profit

Financial autonomy of public hospitals: This has been achieved at the expenses of accessibility for many. The share of health expenditures in the total income has skyrocketed during the last 35 years. In 1990, per capital health expenditures in urban areas were still contained at a very low level of $26 \mathrm{RMB}$, whereas they were reaching more than 1,000 RMB in 2013.

Another effect of the financial autonomy of public hospital has been a certain loss from authorities over medical practices.

Managerial autonomy: In parallel, hospitals have autonomy in personnel management for their for-profit activity. For that part of the activity, personnel is not under the same governance and control from the authorities. This coexistence is bound to create tensions, as salary differences appear between the official public salary scale and unregulated salaries of the for-profit activities. Additional benefits can be granted to physicians and other medical personnel, based on very untransparent, leading to many frustrations. Pursuit of profit can become top priority when it was totally disregarded in previous situation. The objective function of medical personnel includes an increasing component of profit maximization.

Physicians and Financial incentive: In public hospitals, physicians are civil servants (bian₹ $h i^{\text {xviii }}$ ). This status implies certain benefits that will be described later and ensures a fixed income, independent from their volume of activity. Yet, this fixed income is often described as to be fairly low in the view of both their responsibilities and other revenue sources. An additional income sources has been authorized. It depends of the for-profit activity of the hospital. One can then easily understand that physicians have an incentive to develop the for-profit activities, for instance increasing the number of consultations, delivering over-diagnosis or over-prescribing. In such cases, it is a win-win situation for both medical personnel and hospital management.

In addition, this healthcare system nurtures pre-existing practices of bribes and other types of corruption. They tend to become widespread, creating an increasing tense climate between patients and hospital personnel.

\section{Funding of public hospitals today}

The Chinese healthcare system has long been accused of failing to efficiently deliver healthcare services at an affordable cost. In 2009, a set of reforms were implemented, giving the state a bigger role in the production and distribution of health services.

Nonetheless, public hospitals receive only limited funding from the regulator. Table 2 shows the different sources of funding. It is quite striking that direct public funding from the government only represent a minimal share of the total $(8 \%)$. In reality, the involvement is bigger with indirect funding through public health insurance that are set up, in both rural and urban areas. Companies also participate in the financing of healthcare, accounting for almost one third of the total.

Patients' share account for $50 \%$ of hospitals revenue, but they usually do not bear the totality, as a part of it is covered by public or private health insurance. The covered part has been increasing steadily over the last few years. In the end, out-of-pocket payments of patients rose from 20 percent in 1980 to 59 percent in 2000, but then decreased to around 35 percent today. ${ }^{\mathrm{xix}, \mathrm{xx}}$

A landscape analysis of the market of health insurance in China is presented in Chapter 6. 


\section{Table 2: Funding sources of public hospitals in China}

${ }^{1}$ Out-of-pocket payment: sum paid by patients and not reimbursed by any kind of insurance. It includes $\$ 6$ million from the uninsured and $\$ 26$ million in co-payments from the insured.

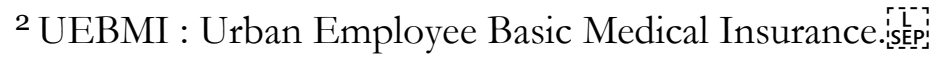

${ }^{3}$ URBMI : Urban Resident Basic Medical Insurance.s[ic:

4 NRCMS : New Rural Cooperative Medical System.

5 «Other » includes private health insurance (both supplementary and stand-alone); employer contribution to group private health insurance, which is around $\$ 1$ million. Total funding is around $\$ 7$ million.

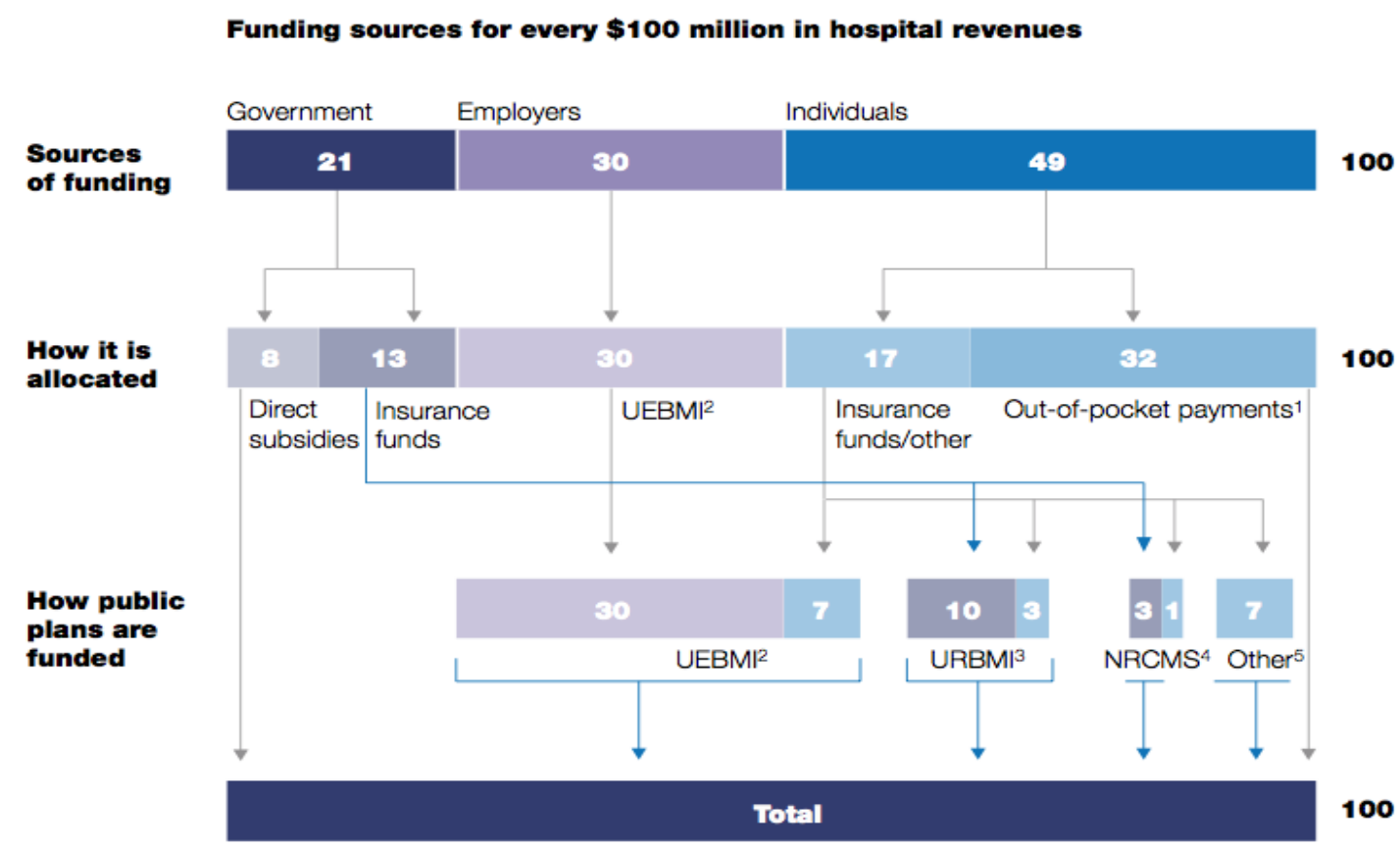

Source: Hospital interviews; government statistics 2010

"Healthcare In China"'isept Kieger Report on the Chinese Healthcare Market 2015

www.mckinsey.com/...service/healthcare $\% 20$ systems $\% 20$ and $\% 20$ services/health $\% 20$ international/hi10_china_healt hcare_reform.ashx

\section{Early forms of prospective payment in China}

Some experimentations, presented here, aimed at switching from a Fee-For-service payment to any forms of prospective payment. The goal is to modify incentives for healthcare providers: from driving up service prices to introduce and encourage competition with a price ceiling system. In urban areas, the insurance schemes existing before the economic reform were based on a principle of regulated pricing. When the Basic Medical Insurance (BMI) scheme was introduced, a mechanism to contain expenditures from the demand side was implemented (Medical Savings Accounts_MSA). On the supply side, there was no change in the provider payment introduced by the central government. However, at local government level, examples of implementation of some form of prospective payment can found and this, from the early BMI pilot.

In 1997, the Social Insurance Bureau of Hainan Province implemented a prospective payment, concerning six key hospitals. This payment was quite similar to a global budget system. Studies leading by Yip and Eggleston (2001 and 2004) ${ }^{\text {xxi,xxii }}$ show that average expenditure by admission fell below that of other hospitals paid by fee-for-service. Besides, spending growth on expensive drugs 
and high-tech services were reduced dramatically. ${ }^{\text {xiii }}$ The strong limits of these studies concerns the fact that the data were not available to control for the potential reduction of quality of care, risk selection, cost shifting to the uninsured. Implementation of similar forms of prospective payment systems nonetheless implemented in many areas throughout China, as in Qingdao, Shandong province, for instance. ${ }^{\text {xiv }}$

Some other cities introduced payment per capita as an alternative prospective payment form. In 2001, Jiujiang city switched to capitation: a fixed amount per capita (contrary to per inpatient or per inpatient day as presented so far) on a defined geographic area. Medical expenditures per insured inpatient fell dramatically and the share of drug expenditures in total spending fell drastically. ${ }^{\mathrm{xx}}$ However, the lack of information of the impact on the healthcare level of quality prevents from any conclusion.

\section{First implementation of DRG payment in China}

Diagnostics Related Group (DRG) payment is a reimbursement scheme that was first implemented in the US at the beginning of the 80 's.

This type of payment is a form of prospective payment system and consists in a lump sum based on the pathology and procedures realized on the patient. A categorization of pathologies, diagnoses and acts is made ex-ante. All patients are affected in one these categories, called Diagnosis Related Group (DRG).

Each DRG defines a pathology, associated diagnoses and all procedures already realized or yet to be realized. This way, each patient falls into a DRG and each DRG corresponds to a pre-defined lump sum, based on the expenses the hospital has to incur to carry out treatment for this type of patient. The advantage of this lump sum is that it is not correlated to the treatment actually performed while covering the theoretical expenses necessary to cure the patient. This gives an incentive to limit cost, explaining while this type of payment is widespread, not only in China but in a vast majority of OECD countries.

The efficiency of such system relies vastly on the quality of information system that goes with it. It is quite complex, as, for each patient, information regarding diagnoses, procedures and comorbidities is to be collected and compiled. China aims at putting in place a comprehensive information system with medical history and admissions of patients. This project is still in the early stages though.

Zhenjiang, a BMI pilot city, started to experiment with a DRG payment system for 82 diseases. ${ }^{\text {xvi }}$ Reimbursement rate for each disease was set according to average expenditure incurred over the previous three years in treating each disease, minus any "unreasonable" expenditure ${ }^{\text {xxvii }}$. In 2003, the average spending for diseases using DRG payment was $25 \%$ lower than the province average in hospitals of the same level hospitals. Once again, because of the poor quality of data at microlevel, studies on the impact of DRG payment system on the quality of care and risk of selection impact have unfortunately not been published yet.

After that, DRG-based payment systems have spread across China. For instance, Cities as Guangzhou, Dalian, Liushou, Mudanjiang. In Guangdong province, as early as 2002, a total of 13 out of 18 municipalities were already using such system. However, this DRG based payment is restricted to some specific diseases. Besides, these cities use also different prospective payment system alongside a fixed charge per inpatient. Studies on these studies provided less strong evidence 
on DRG based payment or other forms of prospective payment on a reduction of healthcare spending. ${ }^{\text {xxviii } x x i x}$, xxx

Following the BMI offices example, some local offices of NCMS (public health insurance for inhabitants in rural areas) ${ }^{\mathrm{xxi}}$ adopted a prospective payment system to reimburse the health providers. For instance, two counties in Shaanxi province adopted a fixed-price reimbursement system on some selected Township Health Centres (THC) and selected County hospitals according to specific criteria. ${ }^{\text {xxii }}$

Besides, some providers moved from a FFS service to a prospective payment system without conjunction with a public insurance. In Heilongjiang province, by the end of 2000, 16 hospitals started to use a DRG based payment system. One goal was to attract private investment and more business by developing a reputation for transparency in pricing ${ }^{\text {xxiii xxxiv }}$ So far, there is not scientific study paper on the effect on quality of care and strong evidence on healthcare expenditure.

Because of no conclusive results, in 2017, these different forms of prospective payment are still in study. This is an on-going field of research.

\section{Private health establishments}

\section{Is the private hospital sector really booming?}

We use here private in a wider sense, to qualify all hospital structures apart from the public ones (minying), be it through joint-ventures, cooperatives or private structures with international or HK, Macao and Taiwan capital.

Until 1980, it was legally impossible to set-up a private hospitals. Different reforms since then have been directed at developing them, along with the financial autonomy of public hospitals. As of $2005,15.9 \%$ of hospital were registered as private structures, most of them being specialized establishments. Nonetheless, the average size of private hospitals is much smaller than public hospitals. In 2008, the average number of inpatient beds for a private hospital was 42 , which is in sharp contrast to the average number of 228 beds for a public hospital. ${ }^{\text {xxv }}$

Recently, when classifying hospitals by their ownership, $58 \%$ of the hospitals in China are public, including state-owned and indirectly state-owned ones, the remaining $42 \%$ are private. In terms of level according to the official hospital classification, the percentage of publicly owned hospital by admissions is $96 \%$ for Level III and $91 \%$ for level II hospitals. As a result, $90 \%$ of Chinese patients choose to visit public hospitals. Private hospitals in China only account for around $10 \%$ of the service volume and for $14 \%$ of beds while being operated at a lower level. ${ }^{\text {xxvi }}$ The picture is quite the opposite of the US, where public hospitals make up 15\% of total hospitals and only $27 \%$ of patient visits. ${ }^{\text {xxvvii }}$

Figure 3: Hospital ownership by hospital level 


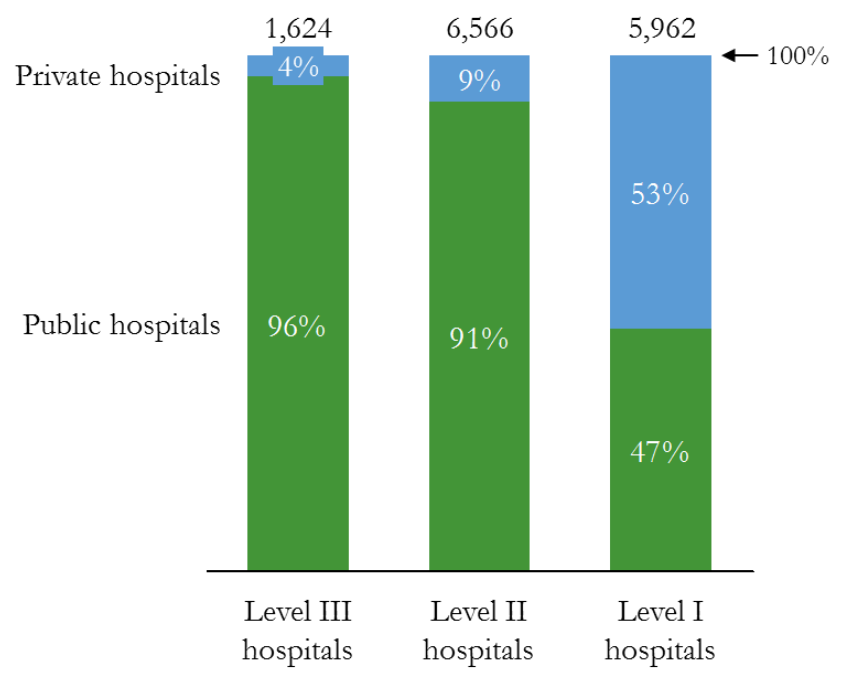

Source: NHFPC (2014), figures from 2012

Nonetheless, the private hospital sector has been steadily increasing over the last few years. In 2013 , the share of beds in private hospitals reached $15.6 \%, 1.6 \%$ up from the previous year. The number itself of public hospitals grew from roughly 5,400 in 2008 to 10,877 in 2014. ${ }^{\text {xxxiii }}$ From 2012 to 2013, the number of patients treated in a private hospital grew by $1.1 \%$. We then observe a constant trend of increase but no sharp change.

Figure 4: Number of public and private hospitals in China

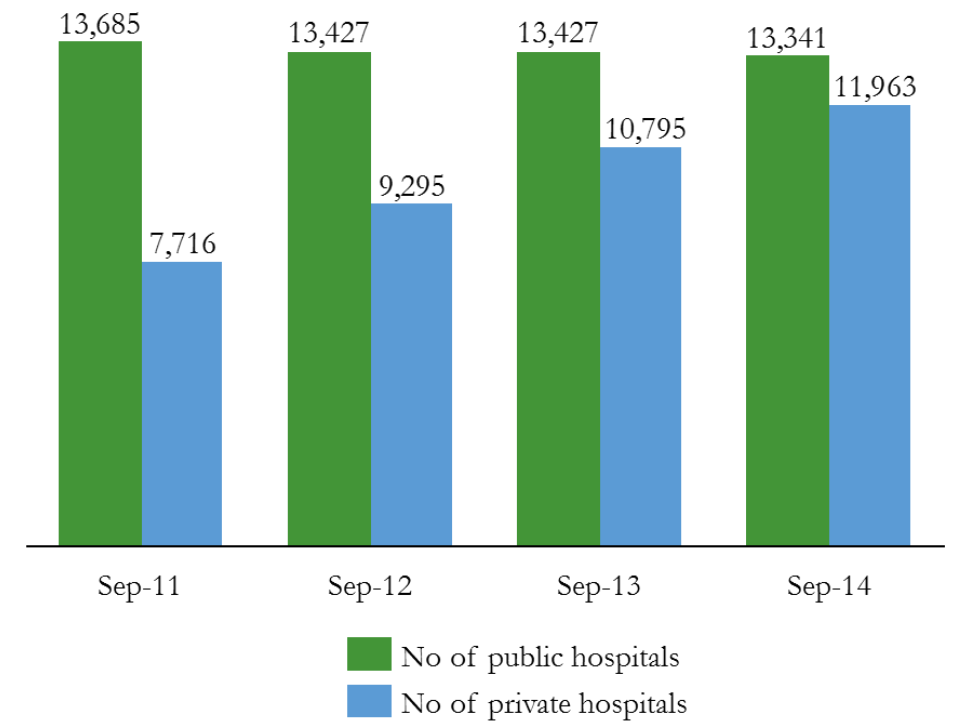

Source: NHFPC (2014)

In rural zones though, the situation is totally different. A big part of primary cares are carried out in dispensaries that are now almost exclusively private and paid on a fee-for-service mode. Yet, it is quite difficult to precisely measure the actual progression of the activity of private healthcare 
establishment. Until very recently, the information on the public or private status of hospital was not made available in official statistics.

As a conclusion, the number of private healthcare facilities is increasing but in terms of number of visits, there is no private hospital booming.

\section{How to explain the difficulty of the private hospital sector growth?}

The Ministry of Health has stated in various occasion its will to develop the private health sector. The objective set by the State Council is for it to command $20 \%$ of the market by 2020 . Why such a support? As previously explained, public hospitals are largely in monopoly situation in their geographical area. The decrease in public funding has mechanically led to a deregulation of healthcare pricing. The partially stated goal is here to increase competition between public and private hospitals to help better regulate pricing. This is very similar to the mechanism in place in the United States for a large part of the population. Using competition between public and private sectors to better regulate hospital care is also increasingly popular in a number of European countries (Germany, UK, Netherlands, France...).

In China, the $12^{\text {th }}$ five-year plan (2012-2016) and the $13^{\text {th }}$ five-year plan (2016-2020) after it emphasize the development of private hospitals. Until then, setting up a private healthcare structure had been legally possible for two decades, but almost impossible in practice, in particular due to difficulties to hire medical qualified personnel ${ }^{\mathrm{xxix}}$. Private hospitals have been addressing in priority three markets segments: high-end healthcare for expats and affluent local population, healthcare targeted to very specific pathologies and finally healthcare in direct competition with the offer of public hospitals.

The first segment enjoys sold growth. Initially directed at expat consumers, it turns out to be more and more used by high-end consumers. "Half of our outpatients are expats working or living in China, such as diplomats and executives of foreign-invested companies. And the other half is highincome Chinese residents. We sell by word of mouth, » said Zhu Ying, President of the Beijing Bayley \& Jackson Medical Center in downtown Beijing, a private hospital with headquarters in Hong Kong. ${ }^{x l}$ Here is an example of what can be observed in very big cities in China. However, so far, this phenomenon is too new to draw more conclusion than this first assessment.

In the third segment, that of private hospitals in competition with public structures, they sometimes have to face distorted competition, through public subventions. But they also have to overcome the difficulty to attract the best practitioners and the prevention from the public towards a new structure without track record nor endorsement from the community. This difficulty to attract patients seems hard to understand in the context of insatisfaction over the service provided by public hospitals. But it actually sheds a light on the priority criteria of patients / customers. The quality and reliability offered by public hospital, through their high level of equipment and skilled and trained personnel prevails over the annoyance of congestion and the price of care.

As explained previously, recruitment of highly skilled professional is one of the main obstacles to the development of private hospitals. The status of physicians in public hospitals, the benefits it brings and the additional wages received in various forms are often roadblock to a migration to a

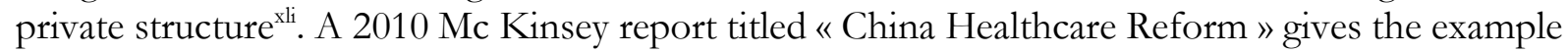
of Beijing municipality ${ }^{\text {xlii }}$.

It addresses Community Healthcare Centres ${ }^{\text {xliii }}$ (CHC) but configuration is identical for private hospitals: «A few cities have tried to force more patients to go to $\mathrm{CHCs}$, but these efforts have 
generallyisepheen unsuccessful. In January 2010, for example, one local government implemented a policy of requiring patients with certain chronic diseases to be treated at a $\mathrm{CHC}$ before they could receive care at a class III hospital. However, the local department of health withdrew this policy one month later, saying that the quality of the CHCs needed to be improved before the policy could be implemented. »

The status and financial obstacles to hire well-known professionals in private hospitals creates a vicious circle with reputation. As they do not manage to hire renowned physicians, private hospitals are obliged to hire young doctors without experience. For both patient and professionals, this type of structure tend to become a second choice, when public hospitals are not an option. The story of An Hua and Li Peng gives a good example. They are reputed physicians in hospital level 1 in Beijing. They confided that working in a private structure could resolve their current difficult working conditions. Where they work, they have to deal with the extended number of working hours, the excessive number of patients and the patient-hospital staff noxious climate. However, according to them, the size of the private facilities is too small to attract a sufficient number of patients; the healthcare equipment is too limited; the professional environment does not provide a sufficiently stimulating setting in which to work and grow. ${ }^{\text {xliv }}$ This difficulty to recruit is a recurring difficulty mentioned by professionals as well as academics. Dr. Wang Zhen, from the Chinese Academy of Social Sciences (CASS) gives the example of the creation of a private hospital in Shenzhen in 2012. It was a showcase collaboration between Hong King University (HKU) and the Shenzhen municipality. In 2015, this state of the art facility has not managed to fill in all the physician open positions. Out of 300 full-time positions, 100 are yet to be filled, to a point it is seriously considered to shift the establishment to a public status to solve the recruitment issue ${ }^{\mathrm{xlv}}$.

In parallel, another obstacle to the development of private hospitals is the restrictive conditions on healthcare expenses' reimbursement by public insurance. It does not include the reimbursement of healthcare in private facilities. However, a main part of the population can afford to get healthcare access only owing to the public insurance. As a consequence, the restrictive rule of public insurance excludes a large part of the population to access to private facilities. Recently, in some cases and in some areas, expenses in private facilities are partially reimbursed by the public health insurance. xlvi It could be interesting to assess the effect of such a change on the individual's preference in the choice of healthcare providers ownership.

So far, if some reforms tend to develop the private health sector, there are still some keys determinants that limit this central state support.

\section{A true story of the challenges behind opening a clinic}

Yu Ying, a former physician in a famous Beijing hospital, the Peking Union Medical College Hospital, is a key figure and spokesperson for public hospital doctors. Her Weibo blog (Chinese equivalent of Twitter) has more than 3 million followers. On it, she has been describing her hesitations before leaving the public sector, her difficulties after crossing the bridge, but also the fulfillment it created. ${ }^{\text {xlvii }}$.Yu Ying who had chosen «Emergency Room superwoman » for her pseudo, is one of the few professionals to have left a level 3 hospital to create a private medical center. When she decided to leave her public hospital, her objective was to open her clinic in Beijing city, within the Fifth Ring Road. However, as she explained, the context was not as easy as expected. A series of administrative constraints and administrative barriers prevented her from opening a centre there. All her efforts failed. Having resigned from her previous hospital and given up her civil servant status, returning to the public sector was no longer an option. She decided to take her chance in Chengdu, Sichuan Province, where she tried again to open a private clinic providing the most basic 
medical services. She failed again. During all this period, she used her blog weibo to explain part of her difficulties and obstacles encountered along the way. When I interviewed her, the term "bribery" was never said even if it could be insinuated. As she said, she was able to explain her disappointment without going to far in the criticism done on the local administrative process. In March 2014, she used her weibo account to explicitly call the authorities about her situation asking "Which deputy of the National People's Congress can tell me why it is so difficult for a doctor, who has worked in the country's top-grade hospital for 12 years and has held a doctorate degree after eight years of professional medical education, to open a regular clinic through formal channels?? 'xlviii. The timing was perfect. It was between the plenary session of the National People's congress and the Chinese People's Political Consultative Conference, giving a strong echo to her protest. The outcome was finally positive, even though she had to drop the idea of setting up her own facility. She is now the CEO of a private general clinic in Beijing city run by the Amcare group $^{\text {xlix }}$, a public-private partnership joint-venture, 2 years and half after having resigned from a top public hospital. Despite her 3-million fans, she has to struggle to both, promote the quality of a market-oriented institution and recruit staff member from big public hospitals.

Her experience illustrates the difficulty for medical professionals to open their own private health centre compared to what it can be in most OECD countries.

\section{Regulatory and para-regulatory context for private health structures}

New series of policies: Since 2009, a new series of policies have been released. The goal of these policies is to lower the barrier to entry for the private health establishments. It should create a more adequate business environment and improve the share of private health structures in the healthcare market. In 2010, a notification on «further encouraging and leading social capital to participate in healthcare institutions » was published. $\mathrm{d}^{1}$ This document promotes and encourages social capital to run private hospitals. It covers more practical details information on beneficial policies for running a private health structure. In order to facilitate the development of the private hospital sector, it also allows to lower the entry barriers for private medical institutes with foreign capital. As a pilot experiment, some local governments have released some constraints on public hospitals: for instance, privatization of public hospital is experimented.

The model_chains of private specialty hospitals_: Currently, the private healthcare market develops a model based on chains of private specialty hospitals. More specifically, the medical services provided by the private sector are mostly for dental, ophthalmology and plastic surgery, as well as diagnosis labs and centres. These sectors are medical sectors where customized services may generate higher margins. Maternity is also considered as a potentially profitable sector. For instance, by May 2013, AmCare had assisted in more than 10,000 births and its total revenue soared 50 percent to 300 million yuan (\$49 million). In 2014, U.S.-based Warburg Pincus LLC invested $\$ 100$ million in Beijing-based AmCare Women's and Children's Hospital to support its expansion. Today AmCare accounts for about half of the high-end healthcare market for women and children in Beijing, which is now dominated by private hospitals. ${ }^{\text {li }}$

According to the Roland Berger report illustrated on the following figure, « investors with various backgrounds are entering China's private hospital market. Foreign hospital chain investors, such as Chindex have built up high-end chain hospitals in smaller size in China. Local financial investors, real estate companies and pharmaceutical companies are mostly targeting at mid-end market and specialty hospitals. Pharmaceutical companies such as Shanghai Fosun Pharmaceutical Group aim at broadening their value chain and boost selling of their own drugs by establishing hospitals or participating in public hospital privatization $»$ lii. 
Figure 5: Investors with various backgrounds in 2012

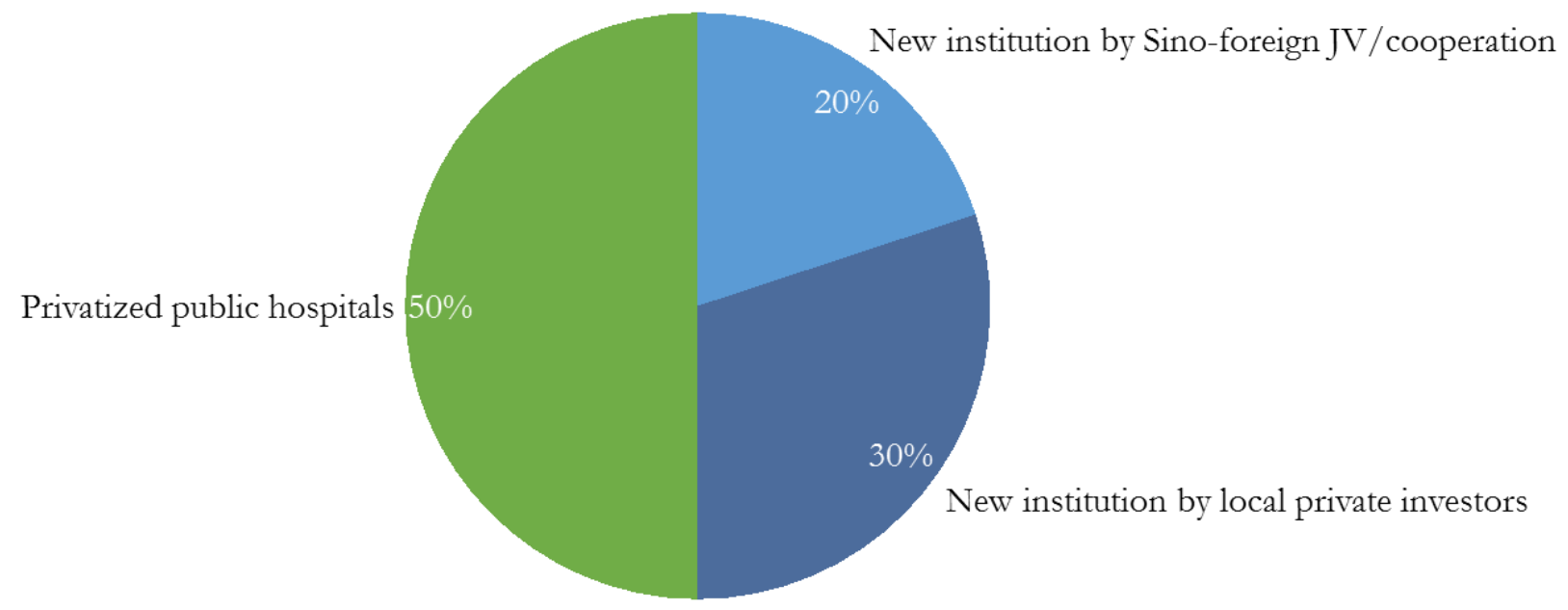

Source: Roland Berger (2014)

A cluster of private medical companies and hospitals owned by people from the city of Putian, commonly known as the "Putian clan" (Putian ji) constitute also an enormous power in the healthcare industry as over $80 \%$ of private medical companies in China are found affiliated with the Putian Clan. ${ }^{\text {liii }}$ The members of the Putian Clan have organized themselves into a chamber of commerce named "Putian (Chinese) Health Industry Association" (Putian (Zhongguo) Jiankang chanye zong shanghui) since 2014.

Public funding and private healthcare providers: Another part of the reform aiming at developing private hospitals is their inclusion into public health insurance scheme. Until recently, a patient admitted into a private hospital was not eligible to reimbursement from public insurance. This constraint is progressively eased, one province after the other. Rules tend to vary depending on the area, but there is an increasing number of cases for which cares provided in private healthcare centers can be covered by public insurance schemes.

In addition, in some provinces or municipalities, private hospitals can be directly subsidized. Again, it is important to be reminded of the decentralized structure of the Chinese healthcare system. General direction and target is given by the central government but provinces have a wide autonomy in the actual implementation. In August 2015, the National Health and Family Planning Commission conjointly announced with the Ministry of Commerce that fully foreign-owned private hospitals were allowed in 7 provinces (Beijing, Tianjin, Shanghai, Jiangsu, Guangdong, Hainan, and Fujian) $)^{\text {liv,lv }}$.

\section{Challenges for private health establishments}

For the future, key variables for private health structures to develop are i) patient recognition that private health establishment can be as trustworthy as a public ones; ii) sufficiently skilled and 
reputable doctors and medical staff including nurses; iii) full inclusion in healthcare insurance schemes.

This first point i) is a pre-requisite condition. The development of the private sector is based on a high level of healthcare quality. The overarching goal of profit maximization must not contaminate the level of quality provided. Few months ago, in press, articles draw attention to private healthcare companies that severely undermines doctor's medical professionalism. As a witness, Doctors, previously employed by Putian-clan hospitals, mentioned that to achieve profit targets set by their superiors performed unnecessary medical treatments. They added that these practices are not uncommon in these hospitals as doctors are directly employed by the hospitals they serve. ${ }^{\text {lvi }} \mathrm{A}$ necessary challenge will be to make profit without undermine the level of quality provided.

Even at a slower pace than anticipated, things are starting to change and the private sectors is now showing significant growth. According to the NHFPC, from September 2013 to September 2014, the number of private hospitals has increased by 1,168, while the cohort of public hospitals was reduced by 86. From 2008 through 2014, visits of patients to private hospitals have increased by $12.5 \%$ from third trimester 2013 to third semester 2014, overstepping the growth of visits to public hospitals, which have accreted at $7.9 \%$ on a quarter-to-quarter basis. .vii

Actually, since the economic reforms from the 80 's, there has been two groups of thought regarding the direction to give to the organization of the health system in China ${ }^{\text {lviii. }}$. One is a promarket group that advocates market liberalism to improve quality of healthcare and efficiency. The other is a pro-government group that advocates the need for a large government role in production and distribution of health services. They prioritize issues of equity or fairness and aim at reducing social inequities. Depending on the period in time, each of this school has had the upper hand on the directions given to reform. The last round of reform since 2013 is very much market-oriented, the market being expected to play a decisive role in the allocation of resources. The third Plenum of the $18^{\text {th }}$ Central Committee of the Communist Party, in November 2013, emphasized higher priority for economic growth. Therefore, the conditions required for the development of private sector in healthcare hospital market are fully in place with favourable policies.

In a near future, with this preferential environment and the ongoing government commitment, a rapid growth of the private sector is to be expected. This evolution should have at least, two consequences. One consequence could be to put pressure on public hospitals and push them to keep going improving their level of quality, not only in terms of medical services but also in the overall service quality (including accommodation, catering ...) and operational efficiency. The other consequence could be to limit the demand for public hospital access (for in-patients and for out-patients) and reduce congestion in the level 3 and 3AAA public hospitals.

These forecasting on the effect of more prominent presence of private healthcare providers in healthcare market are based on a major assumption: the income or wealth of a society is equitably distributed. The hypothesis is very strong and very restrictive. With increasing income inequality, the part of the population who cannot afford to get healthcare access will be increasing. An adequate and efficient alternative may be a performing universal healthcare access for all. However, it may be too costly for the society. It may avoid the failure of market in providing equal access to healthcare. The Healthy China 2020 project includes universal healthcare access by the year 2020 for the basic healthcare supplies. Besides the success of this program, the central question will be what is included in the "basic healthcare supplies" basket. 
${ }^{i}$ Hillier, Sheila, and Jie Shen. "Health Care Systems in Transition: People’s Republic of China. Part I: An overview of China's health care system." Journal of Public Health Medicine. 1996. 18(3): 258-265. ii Wang S. China's health system: from crisis to opportunity. Yale-China Health Journal 2004; 3: 5-49.

iii Ge Y, Gong S. Chinese health care reform: problems, reasons and solutions. Beijing: China Development Publishing House; 2007.

iv Eggleston K., Ling L, Qingyue M, Lindelow M, Wagstaff A. (2008) « Health service delivery in China: a literature review ». Health Economics. 17(2):149-65.

v Du, J. (2009), "Economic reforms and health insurance in China", Social Science and Medicine, 69.

${ }^{v i}$ State Council of PRC. Opinions on further reforming of health care systems. 1992. Available at http://www.reformdata.org/content/19920923/25367.html

accessed September 2017

vii There are a few exceptions to that rule.

${ }^{\text {viii }}$ Eggleston, K., Li, L. and Meng, Q., Lindelow M. and Wagstaff, A., "Health Service Delivery in China: A Literature Review", (2008), Health Economics 17, 149-165.

ix Wang H. "Impacts of medicine price on New Cooperative Medical Scheme", (2005) China Price, 11:23-4, in Chinese.

${ }^{x}$ World Bank. "Taking stock of China's rural health challenge", (2004), Washington, DC: The World Bank.

${ }^{x i}$ Blumenthal, D. and Hsiao, W. "Privatization and its discontents: the evolving Chinese health care system", New England Journal of Medicine, (2005), 353:1165-70.

${ }^{x i i}$ Yip W, Hsiao WC. What Drove the Cycles of Chinese Health System Reforms? . Health Systems \& Reform. 2015 Feb 25; 1(1): p. 52-61.

xiii Chinese MoH: Report of China National Health Accounts. Beijing: China Health Economics Institute; 2009.

xiv Yip, W, William C Hsiao, Wen Chhen, Shanlian Hu, Jin Ma, and Alan Maynard. "Early Appraisal of China's Huge and Complex Health-Care Reforms." The Lancet 379 no 9818 (2012): 833-842.

xv http://www.kaloramainformation.com/article/2014-04/Nearly-40-million-Surgeries-

Performed-China-Last-Year

accessed September 2017

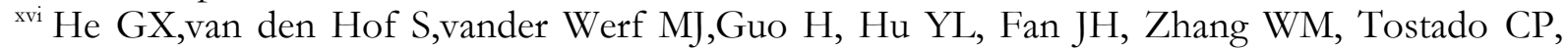
Borgdorff MW. Inappropriate tuberculosis treatment regimens in Chinese tuberculosis hospitals. Clinical Infectious Diseases: Oxford Journals 2011; 52

xvii National Bureau of Statistics of PRC. China statistical year- book. Bejing: China Statistics Press; 2012.

xviii We will see later that bianzhi status sis very specific.

${ }^{\text {xix }} \mathrm{Hu}$, Shanlian, Shenglan Tang, Yuanli Liu, Yuxin Zhao, Maria-Luisa Escobar, and David de Ferranti. "Reform of How Health Care is Paid For in China: Challenges and Opportunities." The Lancet, 2008, 372 no 9652: 1846-1853.

${ }^{x x}$ Kuruvilla S, Schweitzer J, Bishai D, Chowdhury S, Caramani D, Frost L, Cortez R7, Daelmans B, de Francisco A, Adam T, Cohen R, Alfonso YN, Franz-Vasdeki J, Saadat S, Pratt BA, Eugster B, Bandali S, Venkatachalam P, Hinton R, Murray J, Arscott-Mills S, Axelson H, Maliqi B, Sarker I, Lakshminarayanan R, Jacobs T, Jack S, Mason E, Ghaffar A, Mays N, Presern C, Bustreo F, «Success Factors for Women's and Children's Health study groups », 2014. Bulletin of World Health Organisation. 2014; 92(7):533-44.

http://www.who.int/pmnch/successfactors/en/

Source of data is the China Health Statistics Yearbook

${ }^{x x i}$ Yip W, Eggleston K. 2001. Provider payment reform in China: the case of hospital reimbursement in Hainan 
province. Health Economics 10(4): 325-339:S

xxii Yip W, Eggleston K. 2004. Addressing government and market failures with payment incentives: hospital reimbursement reform in Hainan, China. Social Science and Medicine 58: 267-277.

xxiii The authors used a difference-in-difference econometric method using data from June 1995, before the introduction of the prospective payment to June 1997 after the implementation of the prospective payment for six of hospitals.

xxiv Qingdao Municipal Department of Labor and Social Security. 2003. Payment arrangements for contract hospitals. Policy Document No. 52, Qingdao Municipal Department of Labor and Social Security (in Chinese).

${ }^{x x v}$ Jiujiang Health Insurance Office. 2004. The '413' urban health insurance arrangement. Project Report, Jiujiang Health Insurance Office, Jiujiang, Jiangxi Province (in Chinese).

${ }^{x x v i}$ Meng Q. 2002. The impact of provider payment reforms on cost containment. Chinese Health Economics Research 9: 18-20 (in Chinese).

xxvii Wu A, Li Y et al. 2004. DRG-based payment reform for urban health insurance scheme. Chinese Journal of Health Economics 9: 38-39 (in Chinese).

xxviii Meng QY, Rehnberg C et al. 2004. The impact of urban health insurance reform on hospital charges: a case study from two cities in China. Health Policy 68(2): 197-209.

${ }^{x x i x}$ Liu G, Cai R et al. 2003. Reform of medical insurance system in Chinese cities: discussion on equity of cost allocation. Journal of Economics (Quarterly) 2(2): 435-452 (in Chinese).

${ }^{\mathrm{xxx}}$ Wu A, Li Y et al. 2004. DRG-based payment reform for urban health insurance scheme. Chinese Journal of Health Economics 9: 38-39 (in Chinese).

${ }^{x x x i}$ Actually, as said before, the eligibility of the NCMS depends on the rural bukou and sometimes the place of residence.

xxxii World Bank Mission Team, 2004. « Notes for BTOR : Shaanxi Field Visit »

xxxiii Bai Y. 2004. About DRG payment reforms. Modern Medicine 8: 25 (in Chinese).

xxxiv Meng Q. 2005. Review of provider organization reforms in China. China Rural Health AAA Background Report.

xxxv Tang C, Zhang Y, Chen L, Lin Y. (2014) « The growth of private hospitals and their health workforce in China: a comparison with public hospitals » Health Policy and planning. 2014 Jan;29(1):30-41

xxxvi NHFPC (2014)

xxxvii X. Ji, S. Tong, UBS Research (2014): China healthcare: Where to position for growth

xxxviii Ministry of Health website :

https://www.moh.gov.cn/publicfiles/business/mohwsbwstjxxzx/s7967/201112/53508.htm

xxxix See Chapter 4

${ }^{x l}$ Yu Nan «Investment Injection», September 24, 2015. Beijing Review.

http://www.bjreview.com/Nation/201509/t20150921_800038844.html

accessed September 2017

xli See paragraph on bian₹̧i status.

xliihttp://www.mckinsey.com/ /media/mckinsey/dotcom/client_service/healthcare $\% 20$ systems $\% 20$ and $\% 20$ services $/$ health $\% 20$ international/hi10_china_healthcare_reform.ashx

accessed September 2017

xliii $\mathrm{CHC}$ is a healthcare facilities providing care for out-patients.

xliv Interviews in Beijing, June 2015. Translated from Chinese.

xlv Interviews in Beijing, Dr Wang Zhen, Chinese Academy of Social Sciences, September 2015. Translated from Chinese.

xlvi When expenses in private facilities is reimbursed by the public health insurance, the reimbursement rates are lower than those in a public facilities.

xlvii The BMJ Blogs, 23/06/2015.

http://blogs.bmj.com/bmj/2013/09/11/liu-xu-et-al-chinese-doctors-leaving-public-hospitals-

brain-drain-or-emancipation/

accessed September 2017

xlviii Kate Wu, «Yu Ying: China's 'Face of ER' Who Runs New Beijing Hospital » China Youth Daily, January 27, 2016.

http://www.womenofchina.cn/womenofchina/html1/people/others/1601/1728-1.htm 
xlix Amcare Corporation currently operated seven medical facilities for women and children in China in 2015.

${ }^{1}$ The PRC government's No.58 document (03.12.2010): Notification on further encouraging and leading social capital to participate in healthcare institutions

${ }^{l i}$ http://www.bjreview.com/Nation/201509/t20150921_800038844.html accessed September 2017

lii Roland Berger (2014): Entering China's private hospital segment

liii See, for example, Zhang Yue and Wang Leping, "Putian Ji: youyi zhong cheng wangguoZhongguo de minying yiyuan bacheng du shi tamen de" (Putian Clan: wandering doctors become a kingdom - eighty percent of private hospitals in China belongs to them), Southern Weekly.

liv Restrictions loosened on overseas ownership of hospitals, china Daily, August 2015. http://www.chinadaily.com.cn/business/2014-08/28/content_18500131.htm accessed September 2017

lv This rate was about $70 \%$.

lvi Chai Huiqun, "Tamen shi zai biliangweichang pu ji yisheng zi jie yiyuan xi jin shu" ("They are forcing us to be immoral: Putian-clan doctors revealed how hospitals make money), Southern Weekly, 12 May 2016.

lvii China healthcare: 2015 outlook

lviii Zhang $\mathrm{H}$. the argument about the new health reform lines: government and market. The reform and Open-up 2013; 4 :009.

lix 